\title{
The Analysis of Current Situation and Problems of Knowledge Management in the Field of Education in China
}

\author{
Jixin Pan Fuping Guo Liping Liu \\ North China Institute of Science and Technology, Yanjiao Beijing-East 101601, China
}

\begin{abstract}
:
The paper first reviews the literature from the quantitative and qualitative analysis. The results show that the knowledge management mainly focuses on the research of higher education, education theory as well as education management. Moreover, the researchers also focus on elementary, secondary and adult education, but less on preschool, special education and disadvantage education. The application of knowledge management mainly reflects in the school development and school organization, curriculum and pedagogy, teacher education and teachers' professional development, knowledge management tools and its effect on E-education. At last, some problems are pointed out.
\end{abstract}

Keywords: knowledge management; the field of education; application research

\section{Introduction}

The concept of knowledge management can be seen in the field of business administration since 1980s. It is an ideology of management based on the realization that "knowledge has its own value and can create value". The concept and its corresponding thought have been emphasized by the academic and industry circles since it spreads. It especially has made a tremendous effect on educational field, and penetrated into the every aspect of education. In this paper, the author makes an analysis of literatures from the quantitative and qualitative perspectives.
Furthermore, the author presents a comprehensive summary of the current situation, and grasps its development trend to provide a basis for further study.

\section{Data Sources and Research Prepara- tion}

All of the data sources are collected from China Academic Journal Network Publishing Database, China Doctor Dissertation Full-text Database and China Master's Theses Full-text Database. The author chooses Social Science II as collecting scope in the literature classification catalogue, and removes the subdirectory such as social science theory and method, sociology and statistics, ethnology, demography and oligogenics, talentics and laborscience. Moreover, the author takes the title as the retrieval item and knowledge management as the search terms from 1998 to 2011. At last, there are 814 journal articles, 157 master theses and 11 doctoral dissertations retrieved. Through properly screening the collected data, the author then identifies the 812 journals, 11 doctoral dissertations and 157 master theses as valid data.

\section{Quantitative Analysis}

\subsection{Summing up the Data}

Based on the above literature classification catalogue in the three databases, the literature classification of educational field in social science II is mainly about the following eight subcategories: educa- 
tional theory and management, preschool education, elementary education, secondary education, higher education, vocational education, adult education and special education, physical education. The author takes the eight subcategories as the research category. With the statistics, we can see that researches on knowledge management mainly focus on the educational theory and management as well as higher education. There are 844 articles, which accounts for almost $90 \%$. But for secondary education, it accounts for $4.59 \%$, vocational education about $3.16 \%$, adult and special education about $2.45 \%$, physics about $1.74 \%$, elementary education is $1.33 \%$, and preschool education is $0.61 \%$. From the aspect of research category, we find that knowledge management has been too centralized on the educational field, which has led to the unbalanced development of it.

In addition, the author conducts a statistical study on the proportion of the articles in every year in order to grasp the current situation and development trend. Researchers have turned their attention to the knowledge management before 2002; there were more and more researches from 2002 to 2007, but few in 2008, and has tended to be stable from 2010 .

\subsection{Statistical Analysis of Keywords in Journals}

The analysis of keywords could let researcher better grasp the research topic and development trend. By using EXCEL2003, 651 keywords are retrieved, and by resorting to ROSTCM6.0 to process the segmentation of 812 articles, and to analyze the high-frequency words, 769 keywords are collected with the whole frequency of occurrence being 3,334. According to the division between highfrequency words and low-frequency words and word frequency estimation by Sun Qinglan(1992), 40 high-frequency words are extracted. With total frequency of 2,015 that accounts for $60.44 \%$, there are 32 high- frequency words remained after deleting eight ontologism and keywords with broaden meaning

With the analysis of the high-frequency words, it shows that a lot of systematical researches, which mainly focus on teacher education, tacit knowledge, organizational innovation, knowledge share and creation, have been carried out. Distance education, educational technology, social software, knowledge map, virtual learning community, platform and construction are main directions of future researches.

\subsection{Statistical Analysis of Master and Doctoral Dissertation}

Most of post-graduated students and doctors also choose the knowledge managements as their topics. Statistically, there are 11 doctoral dissertations from 8 doctoral institutions, which accounts for $1.1 \%$. During the statistical process of the master theses, 92 master theses could be retrieved from 21 normal colleges as well as 48 master theses from 22 comprehensive universities, 13 theses from universities of science and engineering, and 2 theses from 2 agricultural universities, 2 theses from one foreign language university. It also illustrates that normal universities have played a key role in promoting the research process. Meanwhile, the figure indicates that comprehensive universities account for a considerable proportion besides the normal universities, which explains that knowledge management has been widely studied.

\section{Qualitative Analysis}

In order to make an in-depth analysis, the author makes a qualitative analysis of literatures based on the content of knowledge management, which contains the following 5 aspects. 


\subsection{Application of Knowledge Man- agement in the School Development and Organization}

Zhu Guiqin (2007) has talked about how to construct the school organization culture that was appropriated to knowledge management. Liu Xiaoya (2010) has explored how to improve the digital teaching resource management mode on campus. From the above literatures, it comes to a conclusion that the application of knowledge management to the school development and organization institutions mainly focuses on the school, especially in the high-institutional knowledge management. Most of researchers illustrate the relative theories about the concept, connotation, characteristics, and content of the highinstitutional knowledge management from the perspective of knowledge. Furthermore, there are few researchers paying their attention to the problems, the idea, and the incentive from the perspective of management.

\subsection{Application of Knowledge Man- agement in the Curriculum and Peda- gogy Education}

Wu Xiaolan (2006) has performed an experimental research to put forward the cooperative learning for English in primary schools. Chen Yunling (2009) has led management theories and methods to the improvement of high education classic courses from which the management innovation could be realized. The application of knowledge management to curriculum and pedagogy could be reflected from the following two aspects: (1) knowledge management is put into curriculum and pedagogy as a kind of technology means. (2) The formulation and implementation of curriculum and instructional design could be discussed.

\subsection{Role of Knowledge Management in Teacher Education and Teachers' Pro- fessional Development}

Liu $\mathrm{Li}$ (2005) has held the point of view that personal knowledge managements were approaches for their professional developments. Xiao Min (2007) has made an attempt to find a meeting point of teachers' professional development and knowledge management. Most articles reflect the fact that knowledge management plays an important role in teacher education and teachers' professional development. Some researchers suggest that the best way to promote teachers' professional development is to achieve the balance between the explicit knowledge and implicit knowledge.

\subsection{Knowledge Management Tools and Its Effect on E-education}

Chen Tian et al. (2002) have expounded the application prospect of knowledge management tools in E-education combining all kinds of E-education theories. Liu Hu et al. (2007) have carried out a study on modern distance education resource management from the angle of knowledge management. Li Li (2008) have made a comprehensive study on the educational technology management and constructed the theory framework based on the knowledge management. All of these illustrate that knowledge management is not only a kind of tool, but also a discipline, an industry, and a career.

\subsection{Application of Knowledge Man- agement in the Other Educational Field}

Wang Huizhai et al. (2004) have used case study to discuss the function, organizational framework, and implementation, and made some suggestions about how to perform knowledge management in Beijing Olympic Games. Du Jun (2006) has probed into the relation between learning society and personal knowledge management. Cui Jianhua (2007) has re- 
searched the role of knowledge management playing in the graduate education. As a cross-science discipline, knowledge management has pierced into every aspect of education, although it was not perceived as a panacea.

\section{The Problems Existed in the Appli- cation of Knowledge Management}

From above, we can see that knowledge management has been involved in all aspects of the field of education. However, there are still some problems need to be solved, and mainly reflected in the following two aspects.

\subsection{The Quantitative Analysis}

From the analysis of the content of knowledge management, the research is comprehensive. Researchers have discussed the applications of knowledge management in different categories of education from different perspectives. However, it also reflects the study is not mature. In addition to the focused researches on higher education, educational theory and management, the study on special education and socially vulnerable group's education is almost a blank, which is needed to be solved by scholars. Because the research categories and methods are closely linked, the research method is too single and the research process tends to be programmed with perplexing research categories and concentrated research scope. Therefore, currently the knowledge management in the field of education is too simple and general, and lack of in-depth investigation and research, the scientific empirical research methods are not fully valued, and does not have practice and empirical research foundation. In addition, due to the discipline of knowledge management with intersecting, foundational and applied characteristic, the concept and practice of knowledge management have penetrated into other field, which facilitates the comprehensive use of many methods in multi-disciplines to promote academic cooperation and communication.

\subsection{The Qualitative Analysis}

The current researches primarily embody in the school development, curriculum and pedagogy, teachers' professional development and E-education. For the school development, knowledge management is mainly on the theory discussion, empirical research is still very deficient. Particularly, middle and primary schools, occupation technical schools and adult education organizations are required to have extensive management practice and exploration. From the analysis of curriculum and subject teaching, although the papers are increasing in number, many courses and subjects just take the concept of knowledge management as reference, and fit in the way of other disciplines' methods and ideas, they do not find the corresponding point between curriculum and knowledge management, much less for innovation. From the perspective of teachers' professional development, scholars have gradually realized "people" is the core of knowledge management. However, at the same time of the view of teacher-oriented, the application view of student-centered is ignored. From the e-education point of view, the knowledge management is often in a spontaneous state, and lack of systems and platforms corresponding to information technology. Other problems, such as ethical and cultural exchanges, online public personal privacy and students' communication and cooperation in the distance education, brought by the development of information technology hinder it to go smoothly.

\section{Conclusion}

In short, the research on knowledge management in the field of education is in full swing in China, with new research categories and content and diversified research methods. The focus of study has 
found a balance from the three elements: technology, human being and process. However, it could also be discovered that it is lack of deep understanding of the connotation of knowledge management and its background conditions. Secondly, knowledge management is considered as a universal tool and being mobile in the educational field. Last, much of the implementation of strategy and prospects in the application of knowledge management is just macroscopically constructed and never has microcosmic concrete operation from the systematic and procedural point of view. In fact, knowledge management is a double-edged sword; educators need to move forward to make it play its full role.

\section{References}

[1] Sun Qinglan. The Boundary of High Frequency and Low Frequency Words and Frequency Estimation Method. Information Science, vol. 13, no. 2, pp. 28-32, 1992.

[2] Zhu Guiqin. The Construction of School Organization Culture from the perspective of Knowledge Management. Journal of Teaching and Management, vol. 24, no. 19, pp. 79, 2007.

[3] Liu Xiaoya. Study on the Application of Knowledge Management in Instructional Resources Management of Digital Campus. Kunming: Yunnan University. 2010.

[4] Wu Xiaolan. Research on "the English cooperative learning in primary schools in terms of the knowledgeable management". Journal of Educational Development, vol. 24, no. 8 , pp. 26-28, 2006.

[5] Chen Yunling. Elaborate Course Management Innovation Based on Knowledge Management. China Educational Technology, vol. 30, no. 10, pp, 57-61, 2009.
[6] Liu Li. Personal Knowledge Management and Teachers' Professional Development. Studies in Preschool Education, vol. 19, no. Z1, pp. 5557, 2005.

[7] Xiao Min. Promoting Research on Teachers' Professional Development through the Strategy of Knowledge Management. Global Education, vol. 36, no. S1, pp. 22-25, 2007.

[8] Chen Tian, Yu Shengquan.

Knowledge Management and WebBased Learning. China Educational Technology, vol. 23, no. 5, pp. 63-65, 2002.

[9] Liu Hu, Sun Zhengfeng. The Inspiration of Knowledge Management to Resource Management in Modern Distance Education. China Adult Education, vol. 16 , no. 1, pp. 29-30, 2007.

[10] Li Li. Study on Modern Educational Technology Management from the Perspective of Knowledge Management. Kunming: Yunnan Normal University. 2008.

[11] Wang Huizhai, Lu Shi. Research on Knowledge Management of the Olympic Games. Journal of Beijing Sport University, vol27, no. 9, pp. 1182-1184, 2004.

[12] Du Jun. Learning Society and Personal Knowledge Management. Heilongjiang Researches on Higher Education, vol. 25 , no. 6 , pp. 175-176, 2006.

[13] Cui Jianhua. Tacit Knowledge Management of Postgraduates. Academic Degrees \& Graduate Education, vol. 24, no. 1, pp. 69-72, 2007. 